\title{
Effect of exogenous melatonin on photosynthetic characteristics in cucumber seedlings under cadmium stress: a rapid detection method for the cadmium resistance
}

\author{
Xinyi $\mathrm{Wu}^{1}$, Henggang $\mathrm{Li}^{1}$, Haotian $\mathrm{Luo}^{1}$, Dian $\mathrm{Lin}^{1}$, Xiaoting Zhou ${ }^{1 *}$ \\ ${ }^{1}$ College of Horticulture, Sichuan Agricultural University, Chengdu, 611130, China
}

\begin{abstract}
Water and soil pollution by cadmium have caused severe impact to environment, especially the inhibition of plant growth due to the cadmium stress. Taking cucumber seedlings as the materials, the effect of exogenous melatonin on cadmium uptake and photosynthetic capacity of cucumber seedlings under cadmium stress were studied. The results showed that the leaf area and chlorophyll content of cucumber seedling leaves were decreased after cadmium stress, while the decrease in leaf area was alleviated after the addition of exogenous melatonin. And there was less cadmium content in the roots of cucumber seedlings than that of cadmium stress treatment alone. Exogenous melatonin increased net photosynthetic rate (Pn) with the enhancement of stomatal conductance (Gs), transpiration rate ( $\mathrm{Tr})$ of cucumber seedlings. Further analysis of the chlorophyll fluorescence parameters revealed that the decrease of the effective quantum yield of photochemical energy conversion in PSII (Y(II)), and the photochemical fluorescence quenching coefficient (qP) by cadmium stress treatment were mitigated by addition of melatonin. The results indicated that exogenous melatonin could significantly alleviate the damage of cadmium stress on photosynthetic organs of cucumber seedlings, improve their photosynthetic capacity and reduce the damage caused by cadmium stress. It could be recommended to apply melatonin cultivation of cucumber under cadmium stress.
\end{abstract}

\section{Introduction}

Cadmium (Cd) pollution in soil is becoming more and more serious due to the exploitation and utilization of mineral resources, the extensive use of chemical products, pesticides and fertilizers, and the wanton discharge of municipal sludge and sewage. The latest data show that more than $16 \%$ of the soil area in China is polluted by heavy metals, of which $7 \%$ is $\mathrm{Cd}$ pollution[3]. $\mathrm{Cd}$ pollution not only affects the yield and quality of vegetables, but also endangers human health through enrichment.

Studies have shown that Cd stress can destroy the ultrastructure of cells in plants, inhibit photosynthesis, weaken the absorption of water and nutrients in plants, and adversely affect the growth and development of plants [56]. Cd stress can directly or indirectly promote the production of a large number of reactive oxygen species in plants, leading to the occurrence of lipid peroxidation in cell membranes, resulting in changes in antioxidant enzymes activities in plants, and prompting plants to respond to heavy metal stress [7-8]. Studies have shown that melatonin (MT), an indole derivative of tryptophan, can enhance the ability of plants to resist chilling, low temperature, drought and salt stress [9-11]. At the same time, melatonin has a certain hydrophilic property. It can easily enter the nucleus from the cytoplasm and regulate the antioxidant activity. The use of melatonin to alleviate heavy metal stress has become a new idea for plant safety production. There are many reports about the toxic effects of exogenous melatonin on plants under Cd stress, but most of the studies focus on rices and tomatoes. The effects and mechanism of exogenous melatonin on cucumber and other vegetable crops need further research.

In this experiment, cucumber was taken as the research object, and the effects of exogenous melatonin on cadmium uptake of cucumber seedlings under cadmium stress were determined by measuring the leaf growth and photosynthetic gas parameters of cucumber seedlings. The aim of this experiment was to find way of rapid detection through photosynthetic characteristics, thus make clear the mechanism of mitigation of exogenous melatonin in cucumber seedlings under cadmium stress, and provide more references for stress-resistant cultivation and safe production of vegetables.

\section{Material and methods}

The experiments were carried out in a plastic greenhouse, with a relative humidity $(\mathrm{RH})$ of $60-80 \%$, temperature of $25-28^{\circ} \mathrm{C}$ (day) and $16-18^{\circ} \mathrm{C}$ (night). And light was obtained by natural light. Cucumber (Cucumis sativus cv. Yanqing) were used as materials. Seedlings after germination for 30 days were transferred to $12 \mathrm{~L}$ plastic tubs for hydroponic cultivation provided with halfstrength Japanese Yamazaki standard formula cucumber

\footnotetext{
*Corresponding author's e-mail: 414657644@qq.com
} 
nutrient solution. The nutrient solution changed every 3 days, provided with dissolved oxygen by air pumps.

As for the treatments, the leaves were sprayed with 0 or $150 \mu \mathrm{mol} \cdot \mathrm{L}^{-1}$ of exogenous melatonin at the nightfall until the liquid was evenly covered with leaves, and treated once every 2 days. After three times of treatments, cadmium in the form of $\mathrm{CdCl}_{2}$ at a concentration of 100 $\mu \mathrm{mol} \cdot \mathrm{L}^{-1}$ was added to the culture solution for stress treatment. The second fully expanded leaves from the top of the plants were measured from 10-day-stressed seedlings. Then the plants (12-day-stressed seedlings) were sampled and dried constant weight by the ovens.

For the determination of plant leaf area, after collecting the samples (the second fully expanded leaves from the top of the plants), the sample were laid flat on the grid paper and took photos perpendicularly to the blades by a digital camera. Import images into computer and use Image J software to calculate leaf area. The chlorophyll content of cucumber leaves were determined on the 10th day of treatment by a hand-held chlorophyll meter (SPAD502 type), and five different parts were determined for each leaf. And the cadmium content of the samples were determined by a SP-3520AA atomic absorption spectrophotometer following the method from GB5099.15-2014. Photosynthetic gas exchange parameters and chlorophyll fluorescence parameters were measured by the LI-6400XT portable photosynthesis system (LI-COR, USA) and Pam2500 Portable Modulated Chlorophyll Fluorescence Meter (WALZ, Germany), respectively.
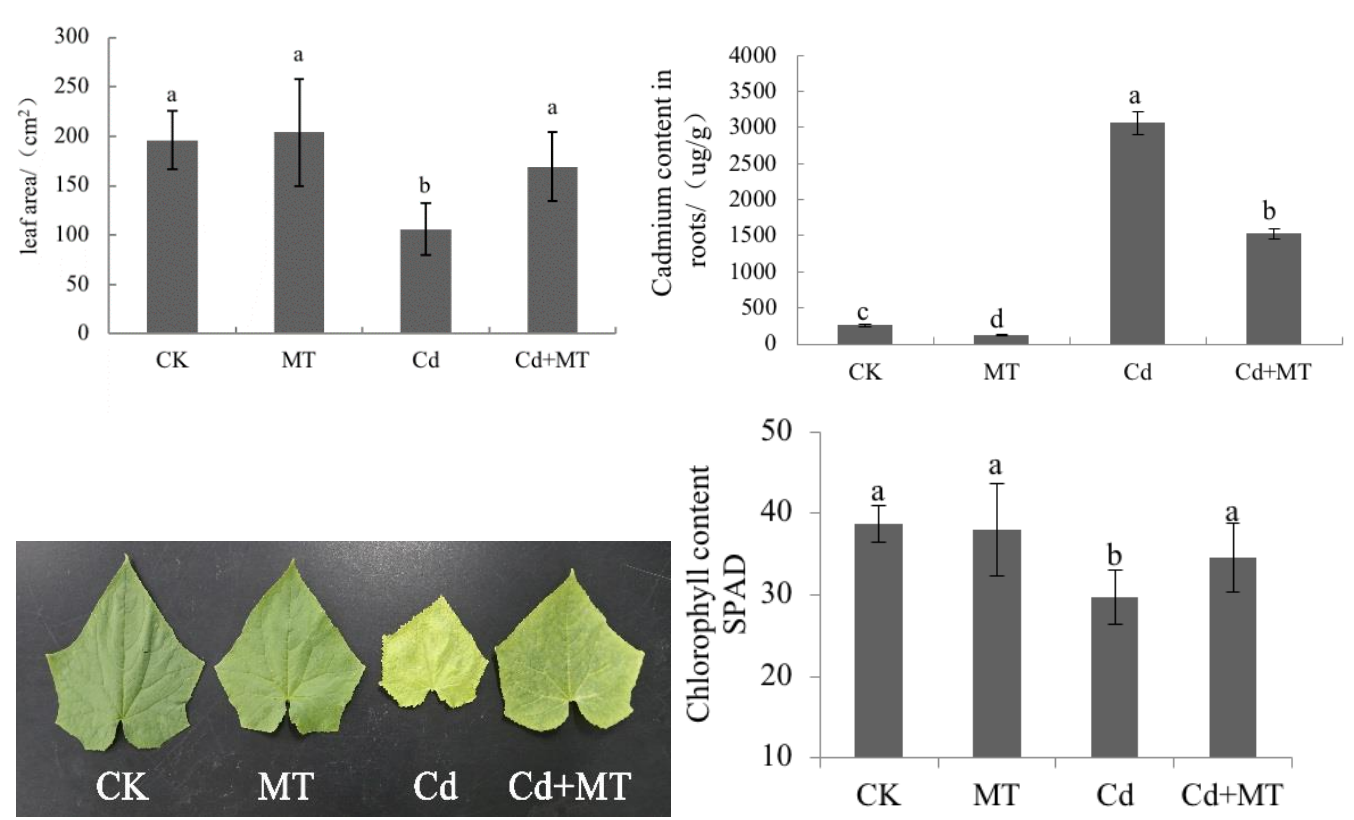

Data processing was accomplished by using SAS statistical software. Values represent the mean $\pm \mathrm{SE}$ standard deviation of 3 replicate samples. Duncan's multiple range test was used for the analysis of variance. Letters indicate significant differences at $\mathrm{p}<0.05$.

\section{Results and discussion}

\subsection{Exogenous melatonin relieved the growth inhibition and excess cadmium poisoning}

It can be seen from Figure1 that cadmium stress decreased the area of cucumber leaves by $45.90 \%$ compared with the control. While the leaf area of the seedlings treated with exogenous melatonin $(\mathrm{Cd}+\mathrm{MT})$ increased significantly by $59.57 \%$ compared with the cadmium stress treatment (Cd). The results indicated that exogenous melatonin effectively alleviated the adverse effects of cadmium stress on the growth of cucumber seedlings. There was less chlorophyll content were decreased under cadmium stress while reversed by the adding the melatonin (Figure 1). The reduction of on photosynthetic pigments by cadmium stress was also found in tomato leaves [12]. In contrary, as shown in Figure 1, the cadmium content in the roots of cucumber seedlings decreased dramaticly by $50.08 \%$ after application of melatonin under cadmium stress. There was consistent result in the effect of exogenous melatonin on the accumulation of cadmium in pea seedlings [13].

Figure 1. Characterization of cucumber seedlings treated with melatonin under cadmium stress. CK indicates a blank control; MT indicates that only melatonin is added; $\mathrm{Cd}$ indicates that only cadmium stress is applied; $\mathrm{Cd}+\mathrm{MT}$ indicates that cadmium-stressed seedlings are treated with exogenous melatonin, the same below.

\subsection{Photosynthesis was significantly enhanced by exogenous melatonin under cadmium stress}

After cadmium stress, Pn of cucumber seedlings decreased significantly by $63.18 \%$. When treated with 
intercellular $\mathrm{CO}_{2}$ concentration of cucumber seedlings whether or not treated with melatonin. Stomatal conductance indicates the degree of stomata opening in plant leaves, and reflects the gas exchange with the outside atmosphere and transpiration of plants. It directly affects the photosynthetic rate and transpiration rate of plants. The stomatal conductance was significantly improved after treatment with exogenous melatonin, and it was improved by $72.33 \%$ compared with cadmium alone. The transpiration rate reflects the equilibrium state of water in plants. The decrease in Tr causes insufficient water supply, resulting in photoinhibition, while the plant reduces the rate of PSI and PSII electron transport in order to avoid photoinhibition [15]. The transpiration rate of cucumber seedlings under cadmium stress decreased by $74.23 \%$. It increased by $102.27 \%$ after treatment with exogenous melatonin, and the difference was extremely significant. There was also rise in cucumber seedlings of the melatonin alone (MT), with $13.86 \%$ higher than the control.

From the table 2, Fv/Fm represents the maximum photochemical quantum yield of PSII, reflecting the potential maximum photosynthetic capacity of plants and damage degree of photosynthetic apparatus. There was no significantly change in $\mathrm{Fv} / \mathrm{Fm}$ among treatments in this experiment. Araus believes that photosynthetic units and membrane-bound electron transport processes are disrupted in swollen, highly disrupted thylakoids, even if Fv/Fm has little or no change [16]. While Y(II) was significantly decreased by $15.72 \%$ in cadmium-stressed seedlings compared with the control, indicating that the activities of PSII were inhibited by cadmium stress. This is consistent with the effect of cadmium stress on PSII in Solanum nigrum leaves[17]. Under cadmium stress, exogenous melatonin $(\mathrm{Cd}+\mathrm{MT})$ alleviated the decrease of Y(II) caused by cadmium stress, increased by $13.58 \%$. Under cadmium stress, the photochemical fluorescence quenching coefficient (qP) decreased significantly, decreased by $16.27 \%$. And the non-photochemical fluorescence coefficient NPQ showed no significant change. The alleviation effect of melatonin $(\mathrm{Cd}+\mathrm{MT})$ in qP increased by $25.79 \%$ compared with cadmium stress.

Table 1. Effect of exogenous melatonin on photosynthetic parameters of cucumber seedlings.

\begin{tabular}{ccccc}
\hline Treatments & $\begin{array}{c}\text { Net photosynthetic rate } \\
\left(\mu \mathrm{mol} / \mathrm{m}^{2} \mathrm{~s}\right)\end{array}$ & $\begin{array}{c}\text { Intercellular } \mathrm{CO}_{2} \\
\text { concentration } \\
(\mathrm{L} / \mathrm{L})\end{array}$ & $\begin{array}{c}\text { Stomatal conductance } \\
\left(\mathrm{mmol} / \mathrm{m}^{2}\right.\end{array}$ & $\begin{array}{c}\text { Transpiration rate } \\
\left(\mathrm{mol} / \mathrm{m}^{2}\right.\end{array}$ \\
$\mathrm{sK})$ & $289.181 \pm 2.7856 \mathrm{a}$ & $0.2934 \pm 0.01589 \mathrm{a}$ & $4.1891 \pm 0.1818 \mathrm{~b}$ \\
$\mathrm{MT}$ & $14.611 \pm 0.9183 \mathrm{a}$ & $288.480 \pm 5.3389 \mathrm{a}$ & $0.3132 \pm 0.02333 \mathrm{a}$ & $4.7695 \pm 0.2401 \mathrm{a}$ \\
$\mathrm{Cd}$ & $14.792 \pm 0.8063 \mathrm{a}$ & $275.926 \pm 14.1272 \mathrm{a}$ & $0.0746 \pm 0.01512 \mathrm{c}$ & $1.0797 \pm 0.1259 \mathrm{~d}$ \\
$\mathrm{Cd}+\mathrm{MT}$ & $5.381 \pm 0.8478 \mathrm{c}$ & $283.416 \pm 2.6802 \mathrm{a}$ & $0.1286 \pm 0.00902 \mathrm{~b}$ & $2.1839 \pm 0.1379 \mathrm{c}$ \\
\hline
\end{tabular}

Table 2. Effect of exogenous melatonin on chlorophyll fluorescence parameters of cucumber seedlings.

\begin{tabular}{cccccc}
\hline Treatments & Fv/Fm & $\mathrm{Fv}^{\prime} / \mathrm{Fm}^{\prime}$ & $\mathrm{Y}(\mathrm{II})$ & $\mathrm{NPQ}$ & $\mathrm{qP}$ \\
\hline $\mathrm{CK}$ & $0.7428 \pm 0.00406 \mathrm{ab}$ & $0.6124 \pm 0.01375 \mathrm{a}$ & $0.5474 \pm 0.01843 \mathrm{a}$ & $0.4420 \pm 0.0288 \mathrm{a}$ & $0.8935 \pm 0.01712 \mathrm{a}$ \\
$\mathrm{MT}$ & $0.7572 \pm 0.00247 \mathrm{a}$ & $0.6225 \pm 0.00992 \mathrm{a}$ & $0.5546 \pm 0.00930 \mathrm{a}$ & $0.5306 \pm 0.1057 \mathrm{a}$ & $0.8910 \pm 0.00612 \mathrm{a}$ \\
$\mathrm{Cd}$ & $0.7234 \pm 0.00657 \mathrm{ab}$ & $0.6167 \pm 0.00242 \mathrm{a}$ & $0.4614 \pm 0.00919 \mathrm{~b}$ & $0.3820 \pm 0.0866 \mathrm{a}$ & $0.7481 \pm 0.01438 \mathrm{c}$ \\
$\mathrm{Cd}+\mathrm{MT}$ & $0.7303 \pm 0.01511 \mathrm{~b}$ & $0.6462 \pm 0.01395 \mathrm{a}$ & $0.5240 \pm 0.01599 \mathrm{a}$ & $0.4169 \pm 0.0495 \mathrm{a}$ & $0.8123 \pm 0.03268 \mathrm{~b}$ \\
\hline
\end{tabular}

\section{Conclusion}

The application of exogenous melatonin changed the content of cadmium in the roots of cucumber seedlings, and significantly promoted the increase of leaf area of cucumber seedlings under cadmium stress; increased the photosynthetic parameters such as chlorophyll content, net photosynthetic rate, stomatal conductance and transpiration rate; alleviated the damage of cadmium stress on photosynthetic organs of cucumber seedlings.

\section{References}

1. Luo, C.L., Shen, Z.G. (2003) Absorption and distribution of heavy metals by plants. Bulletin of Botany, 20(1): 59-66. in Chinese

2. Li, S., Chen, J., Islam, E., Wang, Y., Wu, J., Ye, Z., Yan, W.B, Peng, D., Liu, D. (2016) Cadmiuminduced oxidative stress, response of antioxidants and detection of intracellular cadmium in organs of moso bamboo (Phyllostachys pubescens) seedlings. Chemosphere, 153:107-114.

3. Chen, N.C., Zheng, Y.J., He, X.F. (2014) National soil pollution status survey bulletin. China Environmental Protection Industry, 36(5): 10-11. in Chinese

4. Song, M., Xu, W.J., Peng, X.Y., Kong, F.H. (2013) Effects of exogenous proline on the growth of wheat seedlings under cadmium stress. Chinese Journal of Applied Ecology, 24(1): 129-134. in Chinese

5. Hui, J.A., Dang, Z. (2013) Effects of long-term cadmium stress on the growth and physiological characteristics of maize CT38. Ecology and Environmental Sciences, 7: 1226-1230. in Chinese

6. Liu, S.L., Yang, R.J., Ma, M.D. (2015) Effects of cadmium stress on growth, cadmium content and nutrient distribution of Trifolium repens. Journal of Nuclear Agricultural Sciences, 29(3): 595-604. in Chinese

7. Malecka, A., Jarmuszkiewicz, W., Tomaszewska, B. (2001) Antioxidative defense to lead stress in 
subcellular compartments of pea root cells. Acta Biochimica Polonica, 48(3):687-698.

8. Shah, K., Kumar, R.G., Verma, S. (2001) Effect of cadmium on lipid peroxidation, superoxide anion generation and activities of antioxidant enzymes in growing rice seedlings. Plant Science, 161(6):11351144.

9. Tang, Y., Yu, X.N., He, J. (2017) Effects of exogenous melatonin on physiological characteristics of eggplant seedlings under low temperature and low light stress. Journal of Hunan Agricultural University(Social Sciences), 43(03):257-261. in Chinese

10. Xu, X.D., Sun, Y., Guo, X.Q. (2010) Effects of melatonin on ascorbate metabolism in cucumber seedlings under high temperature stress. Chinese Journal of Applied Ecology, 21(10):2580-2586. in Chinese

11. Xu, X.D., Sun, Y., Sun, B. (2010) Effects of exogenous melatonin on active oxygen metabolism in cucumber seedlings under high temperature stress. Chinese Journal of Applied Ecology, 21(5):1295-1300. in Chinese

12. Lai, Q.Y., Wei, S.H., Dai, H.P., Jia, G.L. (2019) Photosynthetic fluorescence characteristics of tomato and response of cadmium uptake by tomato to soil cadmium pollution. Chinese Environmental Science:1-9. in Chinese

13. Li, D., Wang, Y.F., Wang, Y.H., Wen, X.L., Cai, H.Y., Zheng, X.L., Chen, T.T., Liu, L. (2019) Effects of exogenous melatonin on seed germination, seedling resistance physiology and cadmium content under cadmium stress. Journal of Nuclear Agricultural Sciences, 33(11):2271-2279. in Chinese

14. Gao, Q.H., Wang, Y.K., Lu, X.M., Miao, Y.M. (2014) Effects of exogenous melatonin on growth and antioxidant system of cucumber seedlings under low temperature and low light. Acta Botanica BorealiOccidentalia Sinica, 34(8):1608-1613. in Chinese

15. Wu, K., Wu, Z.H., Tai, F.J., Han, Y., Xie, B.E., Yuan, Z.L. (2011) Effects of cadmium stress on hormone Level, photosynthetic characteristics and fluorescence characteristics of tobacco leaves. Acta Ecologica Sinica, 31(16):4517-4524. in Chinese

16. Araus, J., Hogan, K. (1994) Comparative leaf structure and patterns of photoinhibition of the neotropical palms in clearings and forest understory during the dry season in Panama. American Journal of Botany, 81(6): 726-738.

17. Tang, X.L., Jin, H.P., Zhou, C., Liu, G.Z., Wang, L.Y. (2019) Effects of cadmium stress on chlorophyll fluorescence and photosynthetic biochemical characteristics of Solanum nigrum. Journal of Central South University of Forestry \& Technology, 39(9):102-108. in Chinese 